\title{
Sex susceptibility to ventilator-induced lung injury
}

\author{
Inés López-Alonso ${ }^{1,2,3^{*}}$ (D), Laura Amado-Rodriguez ${ }^{1,2,3,4}$, Cecilia López-Martínez ${ }^{1,3}$, Covadonga Huidobro ${ }^{1,2,3}$ and \\ Guillermo M. Albaiceta ${ }^{1,2,3,4}$
}

\footnotetext{
* Correspondence: ila@lab14.org ${ }^{1}$ Instituto de Investigación Sanitaria del Principado de Asturias, Avda de Roma s/n, 33011 Oviedo, Spain

${ }^{2}$ Centro de investigación biomédica en Red-Enfermedades Respiratorias. Instituto de Salud Carlos III, Madrid, Spain Full list of author information is available at the end of the article
}

To the editor,

Avoidance of ventilator-induced lung injury (VILI), defined as the damage caused by the application of large pressures or volumes to the lung parenchyma, is one of the main objectives of contemporary ventilatory management. This specific form of injury is triggered by a variety of molecular mechanisms involving mechanosensation and mechanotransduction of physical forces, inflammatory responses, activation of intracellular signals, extracellular matrix remodeling, and dysregulation of different forms of cell death. Among these, inflammation plays a key role in the induction of early damage, but also in later repair. In spite of this knowledge, no treatment aimed to reduce VILI based on these mechanisms has been translated into the clinical practice.

The outcome of critically ill ventilated patients depends on the cause of the disease, the specific characteristics of the patient (including comorbidities), and the response to therapies and their consequences. The impact of VILI in outcome falls in this latter category. However, it is not known how previous baseline conditions and applied therapies interact.

Sex is one of the main determinants of health and disease. It has been reported that males show worse intensive care unit (ICU) outcomes [1]. In the specific field of lung injury and mechanical ventilation, females may receive lung protective ventilation less frequently, due to miscalculation of target tidal volumes [2]. Some studies have reported higher incidence of acute respiratory distress syndrome (ARDS) [3] and mortality rates [4] and worse long-term outcomes [5] in mechanically ventilated women, but others have failed to confirm these results [6,7]. The mechanisms behind these differences have been addressed in several experimental studies (reviewed in [8]). Male and female animals have different responses in models of respiratory diseases such as chronic obstructive pulmonary disease (COPD), asthma, and fibrosis. The effects of sex hormones on inflammation and cell metabolism mediate the majority of these differences.

The role of VILI in the difference in ICU outcome between sexes has not been addressed. Most of the experimental research has been conducted in male animals, discarding their female counterparts, and no study has compared male and female animals after mechanical ventilation. To address this question, we ventilated male and female $\mathrm{C} 57 \mathrm{BL} / 6$ mice to induce a moderate lung injury (peak pressure $15 \mathrm{cmH}_{2} \mathrm{O}$, PEEP $0 \mathrm{cmH}_{2} \mathrm{O}$, respiratory rate 100 breaths/minute, inspiratory to expiratory ratio

(c) The Author(s). 2019 Open Access This article is distributed under the terms of the Creative Commons Attribution 4.0 International License (http://creativecommons.org/licenses/by/4.0/), which permits unrestricted use, distribution, and reproduction in any medium, provided you give appropriate credit to the original author(s) and the source, provide a link to the Creative Commons license, and indicate if changes were made. 
1:1, $\mathrm{FiO}_{2}$ 0.21). After $2.5 \mathrm{~h}$, animals were sacrificed and the lungs removed and fixed. There were no differences in lung injury, addressed using a semiquantitative score [9] $(0.5 \pm 0.5$ vs $0.75 \pm 0.52$ for female and male animals respectively at baseline, $2.3 \pm 1.2$ vs $2.2 \pm 1.3$ for female and male animals respectively after VILI, $n=6$ per condition, $p<0.001$ for the effect of ventilation, $p=0.99$ for the effect of sex in a two-way ANOVA). Using a more aggressive ventilatory strategy (peak pressure $20 \mathrm{cmH}_{2} \mathrm{O}$, PEEP $0 \mathrm{cmH}_{2} \mathrm{O}$, respiratory rate 50 breaths/minute, inspiratory to expiratory ratio $1: 1, \mathrm{FiO}_{2} 0.21$ ) yielded slightly higher scores but again without differences between sexes ( $2.5 \pm 1.3$ vs $2.7 \pm 1.3$ for female and male mice, $n=3$ per group, $p=0.88)$. Similarly, there were no differences in neutrophilic infiltrates between sexes $(14 \pm 7$ vs 11 \pm 5 myeloperoxidase-positive cells per field in female and male animals respectively at baseline, $43 \pm 19$ and $37 \pm 15$ myeloperoxidase-positive cells per field in female and male animals respectively after ventilation, $n=6$ per group, $p=0.001$ for the effect of ventilation, $p=0.80$ for the effect of sex). Figure 1 shows representative sections of these studies.

In order to obtain a large-scale assessment of the putative differences between groups, RNA from lung homogenates from baseline and ventilated mice of each sex was obtained and hybridized using expression microarrays (Affymetrix Mouse Gene 2.0 ST, with a coverage above 26,500 genes). Raw data (available at GEO database, accession number GSE121550) were background-corrected and normalized to obtain expression values. These values were fitted to a linear model including sex and ventilation as factors, and $F$ statistics computed with Bayesian moderation of the standard errors. $p$ values were corrected using the Benjamini-Hochberg method. These methods have been detailed elsewhere [9]. Mechanical ventilation induced significant changes in 3510 genes, irrespective of the sex. When comparing the effect of mechanical ventilation between sexes, only 30 genes showed a log-fold change higher than 1.5

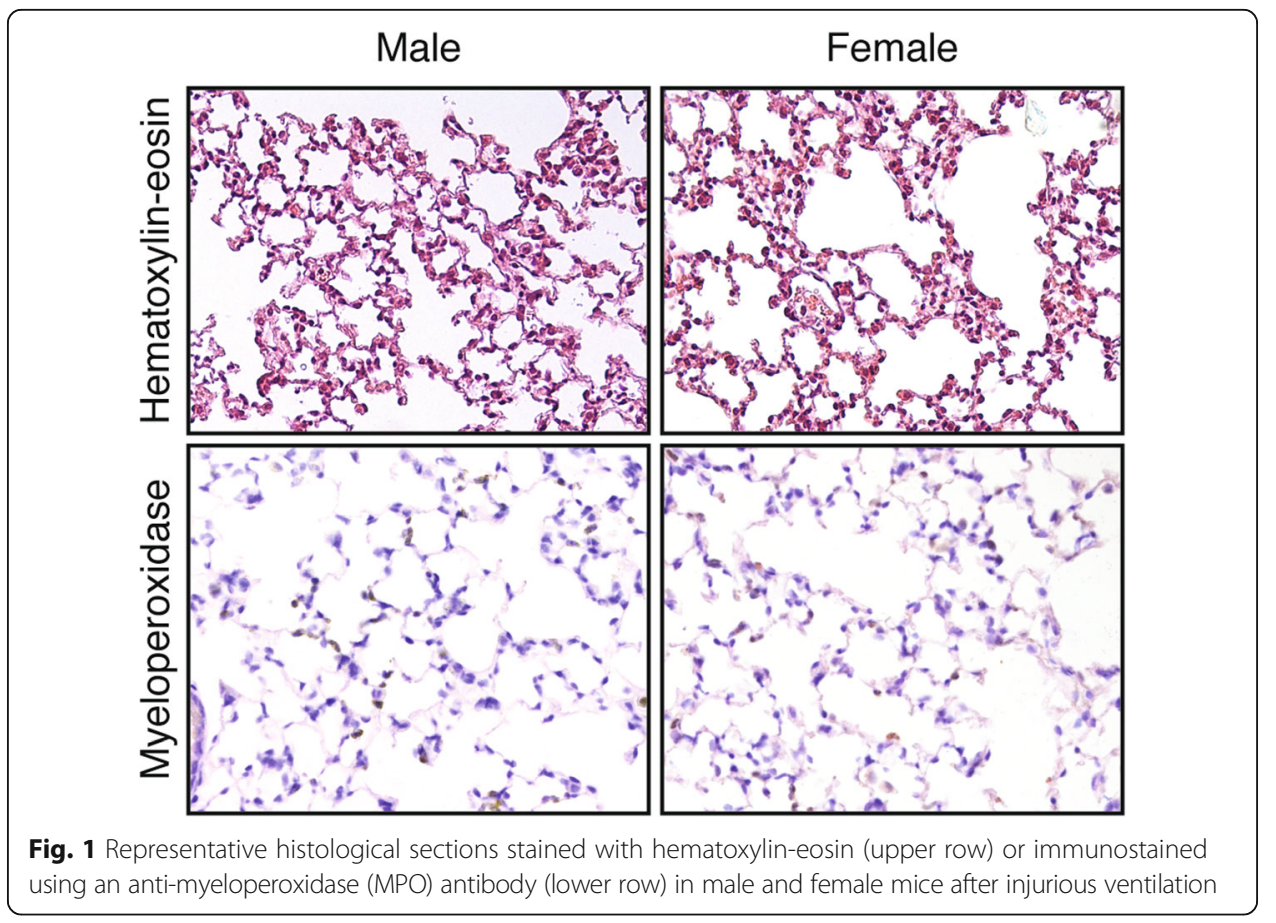




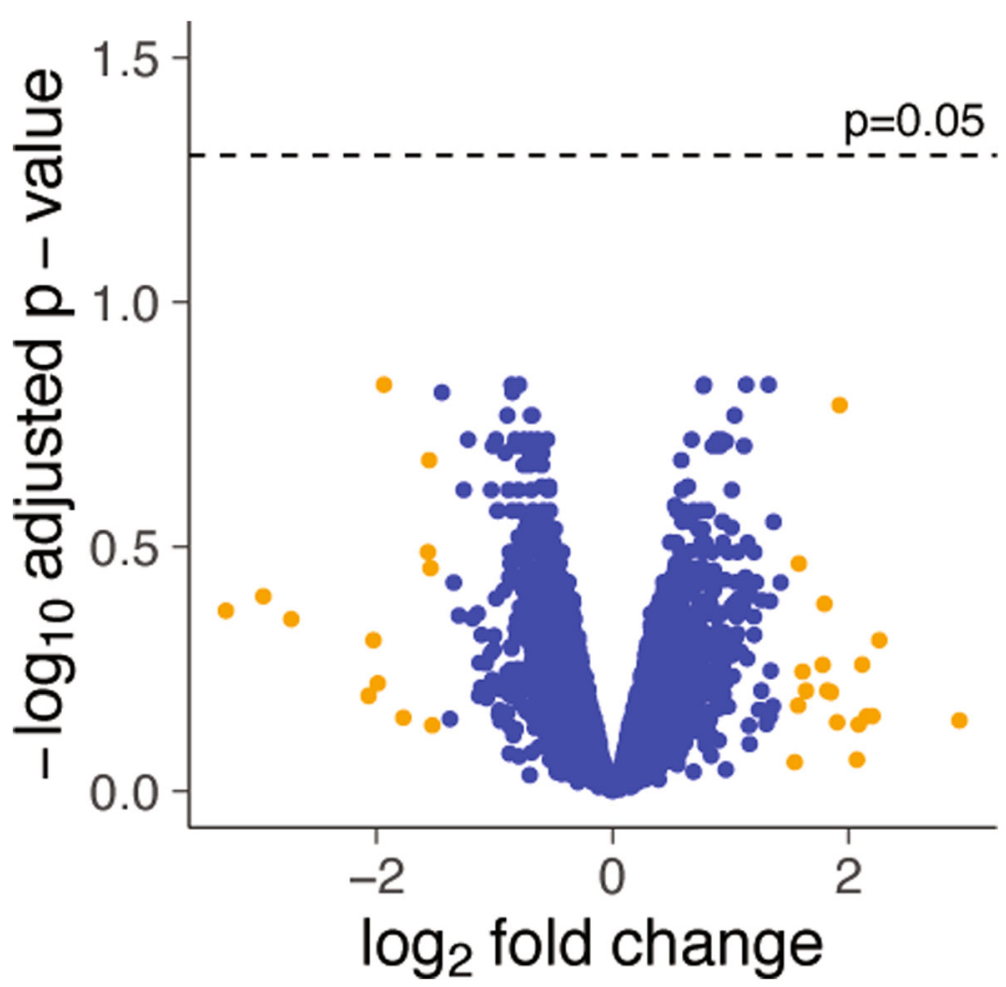

Fig. 2 Volcano plot representing the log-fold change in gene expression with ventilation (comparing male and female mice) against the log of the statistical significance. Only 30 genes (orange dots) had a log-fold change above 1.5, and no gene reached an adjusted $p$ value lower than 0.05

(this is, a 2.8-fold difference between male and female above in the ventilator-induced change in gene expression). Irrespective of the fold change, no gene showed a significant difference between sexes reaching an adjusted $p$ value lower than 0.05 (Fig. 2).

Collectively, these results suggest that there are no differences caused by sex in susceptibility to VILI. Rather than justify the use of animals of a single sex in experimental studies, these findings support the inclusion of both, as advocated by others [10]. Our data allow researchers to assume a hypothesis of no influence of sex, followed by the post hoc assessment of putative differences, if any.

\section{Abbreviations}

ARDS: Acute respiratory distress syndrome; COPD: Chronic obstructive pulmonary disease; ICU: Intensive care unit; VILI: Ventilator-induced lung injury

\section{Acknowledgements}

Not applicable.

\section{Funding}

Supported by Centro de Investigación Biomédica en Red de Enfermedades Respiratorias (CIBERES) and Instituto de Salud Carlos III (FEDER funds, PI16/01614), Madrid, Spain. Instituto Universitario de Oncología del Principado de Asturias is supported by Fundación Bancaria Caja de Ahorros de Asturias. Instituto de Investigación Sanitaria del Principado de Asturias is supported by Fundación FINBA. I.L.-A. is the recipient of a grant from Fundación FINBA. C.H. is the recipient of a grant from Instituto de Salud Carlos III (Contratos Sara Borrell, CD16/00033). L.A.-R. is the recipient of a grant from Instituto de Salud Carlos III (Contratos Rio Hortega, CM16/00128). C.L-M. is the recipient of a grant from Asociación Española contra el Cancer (AECC).

\section{Availability of data and materials}

The rawdata from the expression microarrays generated during the current study are available in the GEO repository, accession number GSE121550 [https://www.ncbi.nlm.nih.gov/geo]. 
Authors' contributions

ILA and GMA designed the study. ILA, LAR, CLM, and CHF performed the experiments and acquired the data. GMA made the genomic and statistical analyses. GMA and ILA drafted the manuscript. All authors contributed to the manuscript modifications. All authors read and approved the final version.

\section{Ethics approval}

The Animal Research Ethics Committee of the Universidad de Oviedo evaluated and approved the study. All the animal experiments were performed according to the Animal Research: Reporting of In Vivo Experiments (ARRIVE) guidelines.

\section{Consent for publication}

Not applicable.

\section{Competing interests}

The authors declare that they have no competing interests.

\section{Publisher's Note}

Springer Nature remains neutral with regard to jurisdictional claims in published maps and institutional affiliations.

\section{Author details}

${ }^{1}$ Instituto de Investigación Sanitaria del Principado de Asturias, Avda de Roma s/n, 33011 Oviedo, Spain. ${ }^{2}$ Centro de investigación biomédica en Red-Enfermedades Respiratorias. Instituto de Salud Carlos III, Madrid, Spain. ${ }^{3}$ Departamento de Biología Funcional, Instituto Universitario de Oncología del Principado de Asturias. Universidad de Oviedo, Oviedo, Spain. ${ }^{4}$ Unidad de Cuidados Intensivos Cardiológicos, Hospital Universitario Central de Asturias, Oviedo, Spain.

Received: 6 December 2018 Accepted: 2 January 2019

Published online: 11 January 2019

\section{References}

1. Mahmood K, Eldeirawi K, Wahidi MM (2012) Association of gender with outcomes in critically ill patients. Crit Care 16:R92

2. Han S, Martin GS, Maloney JP et al (2011) Short women with severe sepsis-related acute lung injury receive lung protective ventilation less frequently: an observational cohort study. Crit Care 15:R262

3. Heffernan DS, Dossett LA, Lightfoot MA et al (2011) Gender and acute respiratory distress syndrome in critically injured adults: a prospective study. J Trauma 71:878-883 discussion 883-885

4. Kollef MH, O'Brien JD, Silver P (1997) The impact of gender on outcome from mechanical ventilation. Chest 111:434-441

5. Brown SM, Wilson EL, Presson AP et al (2017) Understanding patient outcomes after acute respiratory distress syndrome: identifying subtypes of physical, cognitive and mental health outcomes. Thorax 72:1094-1103

6. El-Haddad H, Jang H, Chen W et al (2017) The effect of demographics and patient location on the outcome of patients with acute respiratory distress syndrome. Ann Thorac Med 12:17-24

7. Epstein SK, Vuong V (1999) Lack of influence of gender on outcomes of mechanically ventilated medical ICU patients. Chest 116:732-739

8. Card JW, Zeldin DC (2009) Hormonal influences on lung function and response to environmental agents: lessons from animal models of respiratory disease. Proc Am Thorac Soc 6:588-595

9. López-Alonso I, Blázquez-Prieto J, Amado-Rodríguez L et al (2018) Preventing loss of mechanosensation by the nuclear membranes of alveolar cells reduces lung injury in mice during mechanical ventilation. Sci Transl Med 10:eaam7598

10. Clayton JA, Collins FS (2014) Policy: NIH to balance sex in cell and animal studies. Nature 509:282-283

\section{Submit your manuscript to a SpringerOpen ${ }^{\circ}$ journal and benefit from:}

- Convenient online submission

- Rigorous peer review

- Open access: articles freely available online

High visibility within the field

- Retaining the copyright to your article

Submit your next manuscript at $\boldsymbol{\nabla}$ springeropen.com 